\title{
Research on How to Deal with the Dilemma of Global Cooperative Governance of Cross-Border Telecom Network Fraud in China
}

\author{
Yingchao Geng \\ School of Government, Beijing Normal University, Beijing, China \\ Email:1012297229@qq.com
}

How to cite this paper: Geng, Y. C. (2017). Research on How to Deal with the Dilemma of Global Cooperative Governance of Cross-Border Telecom Network Fraud in China. Chinese Studies, 6, 249-263. https://doi.org/10.4236/chnstd.2017.64023

Received: November 2, 2017

Accepted: November 27, 2017

Published: November 30, 2017

Copyright $\odot 2017$ by author and Scientific Research Publishing Inc. This work is licensed under the Creative Commons Attribution International License (CC BY 4.0).

http://creativecommons.org/licenses/by/4.0/

\section{(c) (i) Open Access}

\begin{abstract}
The rapid growth of cross-border telecom network fraud in the globalized information ocean and the economic tide has posed a threat to China and the global security and stability, and its governance is imminent. Under the analysis framework of global collaborative governance, this paper analyzes the external environmental factors and related internal governance factors, such as the background of cross-border telecom network fraud governance, which needs our attention. From the level of synergetic governance and the autonomy of the subject, the analysis of this paper draws a conclusion that cross-border telecom network fraud improvement is confronted with many dilemmas, for instance, the difficulty in reaching a consensus of values, the malconformation of legal norms, the high pressure of public opinion and the weakness of human nature. The paper puts forward the countermeasures based on Chinese perspective, from four aspects of value guidance, legal soundness, system regulation and technical complementation to work with all parties to manage the main forces, to combat and prevent cross-border telecommunications network fraud, achieving a good prospect of shared governance.
\end{abstract}

\section{Keywords}

Cross-Border Telecommunications Network Fraud, Global Collaborative Governance, Governance Dilemma, Countermeasures

\section{Challenges Faced by Governance of Cross-Border Telecom Network Fraud under the Background of the New Era}

Since the 1990s, globalization has swept across all spheres and social dimensions 
of the globe like a hurricane unprecedentedly. As a product of the integration of global economy and communication, the crime of telecom network fraud has been spreading around the world by the wild wind of globalization. Information globalization provides a convenient access to information resources for the cross-border crimes of telecom frauds, while in the context of economic globalization, the aim of telecom fraud is pointing to the rapid growing mainland China, which has shown a geometrical growth situation in recent years.

\subsection{Information Globalization Becomes the Driving Force of Cross-Border Telecom Network Fraud}

The third scientific and technological revolution has led mankind to the information-based society, and the era of big data based on the internet has come. As the human life becoming more convenient and colorful because of information and technology network, the human society is increasingly dependent on the network and communication technology. Human beings have gradually exposed their personal information to the virtual network society. The lawless members in the society who take the information globalization train stealthily carries on the telecommunication network swindle criminal activity. They obtain the citizen personal information illegally by the direct stealing citizen personal information or the indirect purchase citizen's information and so on, which has formed a black industry chain from collects to sells. As a starting point of mastering citizen's personal information, telecom fraud criminals carry out fraudulent criminal activities by means of modern communication tools, such as We Chat and QQ. Under the condition of globalization of information, criminals try to drill through legal loopholes to carry out cross-border telecommunication network fraud, and they use the information faults in different countries or regions to evade the sanctions of law, for instance, Golden Triangle located in the border areas of Thailand, Burma and Laos.

\subsection{Cross-Border Telecom Network Fraud Focuses on China in the Context of Economic Globalization}

The current world is setting off the third wave of economic globalization and entering the 3.0 era of economic globalization. From 2001 China officially joined the World Trade Organization as the beginning, by 2016 the Group of 20, the G20 summit successfully held in Hangzhou, China's opening to the outside world has entered a new stage. China actively grasps the opportunity brought by economic globalization, and optimizes industrial structure and import and export structure, which realizes the leap-forward development of economy. With the rapid development of China's economy and the increasingly vibrant market economy, China's economic strength and international position in the international economy have been highlighted. The dynamic and potential market in China not only attracts international trade and investment, but also attracts the attention of the telecom network fraud criminals whose hands of crimes into mainland China. 


\subsection{The Telecom Fraud Crime Situation in China under the Impact of Globalization}

In the era of economic globalization and information technology, the crime of telecom network fraud presents a geometrical growth trend with a strong destructiveness and greater ripple, which has great impact on our country's social information, property security and social stability order. Cross-border telecommunications network fraud criminal activities have a growth trend first in the number of cases. According to the official website of the Ministry of Public Security, since 2016, the Ministry of Public Security organized more than 20 police cooperation in Kenya, Malaysia, Cambodia, Laos, Indonesia and other places. Police smashed 58 foreign fraud dens, arrested 975 suspects (of whom 263 people in Taiwan), and detected more than 3000 cases. Secondly, the cross-border telecommunications network fraud cases appear to be diversified and the crime area is diffuse. According to published criminal investigation data of the Ministry of Public Security Bureau, from January 2016 to June, telephone fraud, message fraud and network fraud case numbers rose 36.4\%, 99.1\%, $66.4 \%$ respectively. The foreign-related network fraud crime dens have been shifted from Southeast Asia to Europe, African countries. There are a large number of newly established telecommunications network fraud dens in Spain, Croatia, Greece and other countries in Europe and South America and Peru. From the related data in 2016, there is a significant growth trend of cross-border telecom network fraud in mainland China, and the management of cross-border telecom network fraud is facing great challenge.

\subsection{The Requirement of National Governance Modernization to the Governance of Cross-Border Telecom Network Fraud}

The governance of cross-border telecom network fraud should take full account of contemporary governance ideas and governance ideas to meet the needs of the new era of governance. From the concept of helm and guidance of governance in ancient Greece to the development of governance theories today, and from the diversification of western governance ideas to the modernization of China's national governance, although there are different entry points for governance research, the theory of governance has shown the trend of globalization. The crime of cybercrime is a new crime pattern, which is accompanied by the rapid development of mobile communication and Internet. In recent years, telecommunications fraud has a rapid spread, great damage and other notable characteristics from scratch, from Taiwan to mainland China, from mainland China to Southeast Asia, even Africa, Europe and other global regions. But at present, compared with the news media reports, the research of cross-border telecom network fraud crime is still lagging behind, especially the combination of governance theory and telecom network fraud governance is not that much. In China, the national governance involves the social relations of the national economy, politics, society and diplomacy. And the dynamic development of the modernization of state governance is manifested in the progress and innovation 
in many aspects such as knowledge, urbanization, pluralism and internationalization. The governance of cross-border telecommunications network fraud should be based on the relevant governance theory, and highlight the current concept of governance modernization, and then open a new way of the cross-border telecommunications network fraud governance.

\section{Overview of Cross-Border Telecommunications Network Fraud}

\subsection{The Meaning of Cross-Border Telecom Network Fraud}

According to article No. 266 of China's Criminal Law, the crime of swindling is the act of defrauding the large amount of public and private property by fictitious facts or concealing the truth by means of illegal possession (Xuan, 1984). In the current academic research on the crime of fraud, the definition of the Criminal Law is used more clearly. The concept of cyber-fraud has gradually developed from the original "computer crime" and is now defined as "cyber crime". The network crime takes the computer information network as the carrier, and the trans-regional nature is its important characteristic that the criminal activity is not limited to the specific region. In 2009, our Ministry of Public Security formally gave the definition of "telecom fraud crime". And the telecommunications fraud is illegal possession to defraud the large amount of public and private property which uses the information dissemination function of telecommunication technology based on telephone and computer network and distributes false information to the social groups. In comprehensive, the telecommunications network fraud includes the use of new means of communication as the main form of crime, the use of communication media and computer network information system as a platform to defraud others of public and private property for the purpose of illegal criminal behavior.

According to the relevant concepts introduction, cross-border telecommunications network fraud concept involves four aspects in the fraud subject, swindle object, swindle method, swindle result. The crime subject and the victim are not in the same area or country in the fraudulent activity. The subject of the crime and the victim get the point-to-point contact by telephone. After obtaining the trust of the victim through fictitious facts, concealing the truth and so on, the victims in the fraudulent activities are transferred into the accounts provided by the criminal agents through the bank electronic transfer, and the crime agents quickly transfer the money. It is the cross-border precision telecommunication fraud pattern.

\subsection{The Characteristics of Cross-Border Telecom Network Fraud}

\subsubsection{The Scale of Fraud Organization}

Cross-border telecom network fraud has the systematic organization, entrepreneurial operations, and industrial chain crime. With the help of the convenience of living outside the border, the small fraud team had only a few people initially, 
developed into the more stable criminal gangs with strict division of labor and cooperation. Some telecom network fraud criminals attach to each other and cooperate with each other. They have obvious group, professional characteristics, generally composed by technology, information, call, transfer, withdrawals and other groups of people. Telecom network fraud Criminals profit in cooperation, and set up a fixed partnership to form a criminal network. "Black Industry" chain interlocking and fraud organizations continue to regenerate, which makes it more difficult to eradicate fraud dens.

\subsubsection{The Technology Tools of Crime}

The current cross-border telecommunications fraud is characterized by high-tech and intelligent means. Criminals are familiar with various modern means of communication, the characteristics of payment methods and operating procedures. They are good at using these high-tech's advantages and disadvantages to do criminal activities. On one hand, the technology of cross-border telecommunication network fraud is embodied in the application of high technology in the process of swindling. On the other hand, it is embodied in the asymmetry of technology between criminal syndicate and public security organ. At present, the telecommunications fraud cases has gradually developed to use VoIP (Voice over internet Kyoto) network telephony, hacker technology, U-shield transfer technology from the earliest use of mobile phone message mass device, computer mass software, a number of Qualcomm, 400 bundled telephone technology (Hu, Liu, \& Peng, 2010). At the same time, network technology is an important link for all the crimes of telecom fraud, which needs the maintenance support of network technicians, and completes the crime of swindling through illegal network platform.

\subsubsection{Crime across the Region}

The main manifestations of transnational cross-border crime are remote control, off-site crime, cross-border telephone, cross-border collection. With the rapid development of global informatization and economy, the exchange between China and other countries is becoming more and more frequent and close, which provides a convenient condition for cross-border and trans-regional crime. With the rampant crime of domestic telecom fraud and the soaring amount of money involved, police have stepped up the crackdown on the crime of telecom fraud. The criminal offender has accumulated more and more anti reconnaissance experience in the process of crime development. Although international criminal justice assistance has played a certain role in deterring criminals, the criminals set up the crime lair outside the country and defraud the people in the territory to evade the attack of the investigative organ, or they set up the crime dens in the territory, and defraud the people outside the country. Cross-border telecommunications fraud principals are often remote command behind the scenes, so even if we have captured the criminal suspects who truthfully confessed to the group composition and the main perpetrators, it is difficult 
to thoroughly combat criminal gangs.

\section{The Construction of Global Collaborative Governance Analysis Framework}

Based on global governance theory, cooperative governance theory and multi center governance theory, this paper tries to discuss how to deal with the dilemma of cross-border telecom network fraud governance effectively. The concept of global collaborative governance covers the multiple governance subjects with common interests, including national, regional and international organizations. The object of governance is the crime of cross-border telecom network fraud. We use it as a common governance goal including comprehensively combating Cross-border telecommunications fraud, safeguarding international stability and achieving common interests. Governance mode is the combination of autonomy and governance to construct a benign and orderly network fraud management system.

\subsection{The Design of Global Collaborative Governance Analysis Framework}

Collaborative governance emphasizes the interaction among subjects, and achieves the governance objectives in the collaborative process of governance approach and governance notion. In the interaction mechanism of synergetic governance, Figure 1 shows that the environmental factor is also an important part of this mechanis min addition to self-government and mutual-governance interaction, which affects the achievement of the governance goal and the effect of governance. Therefore, in the process of building the analysis framework, we need to consider the factors that affect governance effectiveness. First, we need to consider external environmental factors, including international political situation, international law stipulation and the sovereignty issue among the countries. They appear in the management of cross-border telecom network fraud, which interferes with the governance idea, the governance mode and the cooperation efficiency among the main bodies. For instance, regional conflicts and the conflict of interest maybe hinder the progress of synergetic governance and influence the effectiveness of governance. Second, the internal factors will affect the methods of choice of cross-border telecommunications network fraud governance and interaction between the participants in the degree of participation, such as the level of economic and social development, the national religious belief and the ability of national quality. The internal and external factors both affect the goal of coordinated governance can be achieved or not.

The multiplicity of governance subjects and the complexity of governance factors make the global cooperative governance of cross-border telecom network fraud face many difficulties. To facilitate the analysis of governance dilemma and choice of governance, this study constructs a global collaborative governance analysis model shown in the Table 1, which is based on synergetic governance theory and multicenter governance theory. According to the degree of 


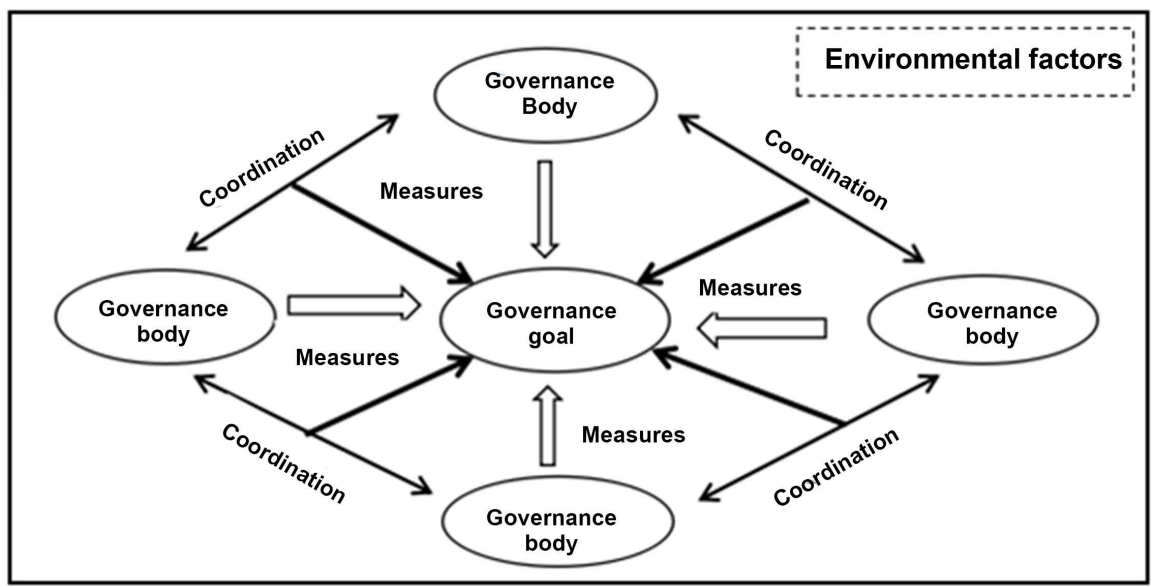

Figure 1. Interactive mechanism of collaborative governance.

Table 1. Global collaborative governance analysis framework.

\begin{tabular}{cccc}
\hline \multicolumn{2}{c}{$\begin{array}{c}\text { Global Coordinated } \\
\text { Governance Strategy }\end{array}$} & \multicolumn{2}{c}{ Degree of Synergy between Governance Subjects } \\
\cline { 3 - 4 } & Weak & Lalue Guidance & High \\
\hline $\begin{array}{l}\text { Individualization of } \\
\text { Governance Subject }\end{array}$ & Strong & Technical Complementarity & Legal Soundness \\
\hline
\end{tabular}

individual performance and the degree of coordination between the governance subjects, this paper puts forward four kinds of cooperative governance methods including value guidance, system regulation, technical complementarity and legal soundness. It analyzes the choices of cooperative governance mode under different dilemma state to realize the goal of combating the crime of illegal and criminal fraud in Cross-border Telecommunication network and to create the international environment of peaceful and stable development.

The main character of the governing body is the governance subject itself in the economic strength, the development level of scientific and technological strength, cultural soft power, foreign policy and so on. The stronger the main body of governance, the greater the degree of individuality of the subject, the more prominent the international status, the greater the international influence, the more obvious the decision-making advantage in international affairs. The coordination between the governance subjects is mainly embodied in the decision-making preference, the relevant interests, the rule of law and the institutional framework. The more similar the decision-making preference among subjects, the greater the proportion of common interests, the higher the degree of synergy between the subjects, the more easy to reach the target.

There are four collaborative approaches in different situations. Firstly, in the face of the weak degree of individualization of governance subjects and the low degree of coordination of governance subjects, we should choose the cooperative governance mode of value guidance, which reaches consensus from the value level to promote the practice of governance institutional norms. Secondly, when 
the degree of individualization of the governance subject is weak and the cooperation degree of the governance subject is high, the system norms should be strengthened to avoid the emergence of information gap and unfair injustice, and to guarantee the information equalization and action coordination among the governance subjects with different development levels. Thirdly, under the condition that the degree of individualization of governance subject is strong and the coordination degree of governance subject is low, the technical cooperation should be the first step to realize the complementary technology in the process of governance, and then gradually it realizes the governance synergy goal. What is more, we should make full use of legal means and perfect the international law to maintain the benign state of synergetic governance, in the case of the high degree of individuation of the governance subject and the cooperation degree of the governance subject. Especially in the governance process of cross-border telecommunications network fraud, the international laws and regulations play an important role to ensure the effective implementation of coordinated governance and to promote governance objectives.

\subsection{The Characteristics of Global Collaborative Governance Analysis Framework}

The global collaborative governance analysis framework has four characteristics of benefit integration, systematic operation, multi-factor containment and stability analysis. First of all, it is holistic. The global cooperative governance analysis framework emphasizes that the governance subject should break its own interests, combine the edges and corners, unite the common interests, and build the global interests to seek the coordinated governance. Secondly, it embodies systematicness. System is composed of a large number of subsystems with subsystem coordination and orderly systematic structure. In the framework of this analysis, each governance body is a subsystem. In the global collaborative governance system, they both have personalized autonomy and the mutual governance between subjects. Furthermore, it is inclusive. Based on this framework, cross-border telecommunications network fraud coordination governance needs to take into account the relevant factors, both external environmental factors and internal factors, including the mutation factors and special factors. The fourth feature is stability. The aim of governance is to stabilize the order, the process is stable, and the vision is long-term stability. The global collaborative governance analysis framework uses four collaborative approaches as a stable tool for appropriate use in different situations.

\section{Cooperative Governance Dilemma of Cross-Border Telecom Network Fraud}

\subsection{The Dilemma of the Common Governance Level}

\subsubsection{The Challenge of Value Concept}

In the international community, national interests are the primary consideration 
of the participation of states in international activities. In a possible case, sovereign states tended to maximize their interests, which would undoubtedly weaken the dynamics and effectiveness of global governance. Cross-border telecommunications network fraud governance involves the governance of the security interests of all subjects, sovereign interests and so on. The interests of the actors involved in global collaborative governance are decentralized, which makes the fight against cross-border telecommunications network fraud in the capacity of the collective action weakened, and the phenomenon of non participation and negative participation. It also facilitates the private interests of some regions and countries. In today's international system, large and small countries coexist. There is a huge structure of asymmetrical value distribution. The position and function of the big and small countries in the global coordinated governance is very different. The regulation and mechanism of global governance are mostly formulated and established by some countries in the West, and global governance inevitably reflects the intention and value of the western countries to a great extent. Therefore, relying on the power of a governing body is difficult to effectively cooperate with all parties to jointly combat cross-border telecommunications network fraud.

Ethnic and religious contradictions and conflicts have become an important obstacle to international relations and international affairs. As a pervasive social and cultural phenomenon, religion not only reflects the spiritual characteristics of the nation or society, but also affects international affairs and world peace and stability. The South-East Asia Mekong River basin is an example of the area of cross-border telecommunication network fraud with high incidence. The popular religions in Southeast Asian countries both have a long history and tradition of primitive religion, and then they form Buddhism, Islam and Christianity. The national religion and the belief have infiltrated into the national language, the way of thinking and the life habit. In South-East Asia, where ethnic composition is extremely complex and ethnic groups coexist, conflicts between ethnic religions are inevitable (Ge \& Liu, 2009). Ethnic religions have formed barriers to the management of cross-border telecommunication network fraud, which restricts the development of cooperative governance and crackdown.

\subsubsection{The Fault of Legal Norms}

Although the United Nations Convention against Transnational Organized Crime, the Convention on Cybercrime, the Strengthening of International Cooperation and the Fight against Cybercrime have been published successively, there is still a lack of international legal consensus on the common legal norms of cross-border telecommunications fraud, the criteria for determining crimes and the technical norms of law enforcement. Cross-border telecom fraud crime often spans the space-time, changes quickly, cooperates with each other, the location of criminals, the victims of remittances, withdrawals scattered in different regions and countries, so that investigative agencies need a lot of manpower and resources (Huang \& Wang, 2016). Owing to different national legal systems and 
imperfect international police cooperation, cross-border arrest of criminal gangs is difficult. In particular, the jurisdictional dilemma, because the scope of cross-border telecommunications fraud crime is uncertain, transnational, as well as national law enforcement technology and law differences, although all the countries involved have jurisdiction, but any country cannot be alone to deal with cross-border telecommunications network crime threat. The difference of laws between different countries has become the key factor that restricts the governance of cross-border telecom fraud crime.

\subsection{The Dilemma of the Autonomy Level}

\subsubsection{Government Faces Internal and External Pressure}

Social public opinion and public focus is the driving force of cross-border telecom network fraud governance. At present, the current major news media track and release dynamic information of cross-border telecommunications network fraud crime. The public obtain information on the development of telecommunications fraud cases through smartphones, computers or televisions. Various social strata pay attention to telecom fraud cases from multiple perspectives. Cross-border telecommunications network fraud has become a social focus of events. In the information age, the main body of governance has also shown a kind of focus effect in the cross-border telecom network fraud management, and the external pressure mainly comes from the mixture of information leading to the guidance of public opinion. Cross-border telecommunication network fraud cases involve public interest, so the public will naturally focus on the development and process of the governance work. But after the public receives all kinds of positive and negative information about the governance work, they will send a mixed voice to the cross-border telecom network fraud management. Cross-border telecom fraud governance, which requires that the main body of governance should take measures to carry out the fraud work and achieve the effect of governance in a certain time. At the same time, Cross-border telecommunications network fraud involves off-site handling, which puts forward higher demands on the manpower and material resources of public security organs. The shortage of police force, the high cost of investigation and the backwardness of investigative technology and equipment have become the unavoidable internal pressure of the government.

\subsection{2. "Internet + Telecom Fraud" Technological Catch-Up}

"Internet + " is the new Internet thinking in the era of information and technology, that is, "Internet + various traditional industries", which integrates the Internet with the traditional industry in depth using information and communication technology and internet platform to innovate the model of economic development. But the telecom network fraudsters rely on the Internet platform for fraud crime, and "Internet + Telecom Fraud" a new pattern of crime gradually formed. In the era of Internet information, cross-border telecom network fraud governance relies on computer network technology to a great extent. But in the 
current technology race between the main body and the crime subject, the governance subject is often in a backward state. In the process of gradual formation of the pattern "Internet + Telecom Fraud", how to break through the technology bottleneck is the key to carry out the management of cross-border telecom network fraud, and the technology leader is the precondition of the success of the cross-border telecom network fraud governance.

\subsubsection{The Weakness of Human Nature}

The weakness of human nature is an important impetus for the fraudulent activities of cross-border telecom network fraudsters, and also a major obstacle to the management of cross-border telecommunications network fraud, so it is necessary to analyze the psychological state of the victims of fraudulent activities. From the scams of telecom networks, criminals often seize the sympathy of the public, greedy desires, curiosity, fear and other psychological implementation of fraudulent criminal activities. For example, criminals use the idea that people generally love to take advantage of petty money, in the name of the award, can tax rebate and so on, lure the victim remittance transfer. Criminals also use blood relatives to care for their relatives and friends, and to cheat the victim for money transfer. Criminals also use people's awe of authority, criminals pass the authority to the victim through the role of intimidation information, thereby defrauding trust, to achieve the purpose of defrauding money. The deception of these telecom frauds comprehensively utilizes the psychological activities of human beings, grasps the common psychological characteristics of the people, and has a strong temptation and lethality to most of them.

\section{Suggestions}

Under the background of the new era, the four challenges faced by the management of cross-border telecom network fraud, including the governance pressure brought about by the globalization of information and economic globalization, the grim situation of cross-border telecom fraud, and the requirements of the modernization of national governance. In the process of cross-border telecom fraud governance, it is confronted with the difficult consensus of value concept, the fault of legal norms, the high pressure of public opinion and the weakness of human nature. The above analysis shows that our country is confronted with the dilemma of cross-border telecom fraud management, which requires us to actively explore the countermeasures from the aspect of co-governance and autonomy.

\subsection{Promote Benign and Common Governance}

\subsubsection{Phased Implementation of Global Governance}

In the context of globalization, a new national interest in a global sense can be combined with the reconstruction of economic, security, social and cultural interests. The national interests are endowed with new connotations in the global governance, and the national interests are no longer judged by whether the tra- 
ditional system is subverted, whether the sovereignty is violated, or whether the territory is intact. The traditional core interests such as institution, sovereignty and territory have been deformed in the reconstruction of economic, security and social interests, and the part of the deformed interests is the real overlap of interests between big powers. We can find the growing point of the reconstruction of the interests among the great powers and find the space for the reconstruction of the interests. And then their interests permeate and depend on each other (Huang, 2013). China, as a responsible country, should be committed to the fight against Cross-border telecommunications network fraud from China's regional coordinated Governance (Taiwan), to regional coordinated Governance (Southeast Asia), and then to the global coordinated governance.

China took the initiative to hand over cross-border telecommunications network fraud. In 2016 when the Ministry of Public Security held in Beijing to combat cross-border telecommunications network fraud briefing, the Ministry of Public Security officials briefed on the overall situation of China's telecommunications network fraud crime, and introduced the organization of such criminal gangs and the process of crime, to promote China to prevent the fight against telecommunications network fraud related experience practices. Transnational telecom network fraud criminal gangs have strict organization and strong concealment. Such cases have the characteristics of difficult detection and recovery, and have the trend of accelerating to worldwide. We need all countries to work together to fight against such crimes.

\subsubsection{Improve the Mechanism of International Cooperation in Combating Cross-Border Telecom Fraud Crime}

Improve the international police cooperation mechanism of the rapid response. On the one hand, we should use the Internet and public security network to establish cross-regional police cooperation, through the establishment of a nationwide shared network technology platform, the implementation of information resources sharing, the construction of rapid response linkage mechanism, the concentration of limited police resources to achieve maximum efficiency, avoiding duplication of labor and police waste. At the same time, according to the actual situation, we should establish a sound operating mechanism and rules around jurisdiction, transfer of evidence and so on, and promote the domestic regional police cooperation more convenient and pragmatic to improve the detection rate. On the other hand, anti-telecom fraud has become an international policing issue, which must continue to promote cross-strait and international police cooperation in order to curb such crimes. We should take such actions from investigation, litigation, supervision, transfer and other links to carry out in-depth research, formulate a perfect and feasible judicial cooperation flow, to achieve international police cooperation is smooth, rapid response, strong cooperation (Lin, 2013).

Construct information communication mechanism to solve information asymmetry, such as the information interchange platform. In the process of 
building telecommunications fraud control system, China's public security organs fully integrate the unique "cross-regional collaboration platform" and "telecom fraud platform", and extend the function and coverage of these two platforms so that this comprehensive platform can be collected through information on the cases of telecom fraud, through the analysis of the telecom fraud crime, to do a good job of early warning, promptly understand the various forms of telecommunications fraud, and ready to prepare for preparedness. In the practice of the telecom fraud prevention and control work, the work process and working methods are constantly tested, corrected and perfected, thus creating a new working mode and a powerful strategic comprehensive platform, which can not only combat the crime of telecom fraud, but also provide technical and informational support to combat other crimes (Cai, 2017). In the domestic formation of electronic information to combat crime, the new mechanism, after maturity, can open up the window and the international criminal network, to achieve global information sharing, cross-border telecommunications network fraud crime form a huge lethality.

\subsection{Overall Optimization of Autonomy}

\subsubsection{China Should Assume Great Responsibility as a Big Country}

Cross-border telecom network fraud governance involves the national sovereignty and national interests of China and other countries. So we should take full account of our country's foreign policy and the concept of modernization of governance in carrying out the governance work. Our country has always adhered to the independent foreign policy of peace, upheld the peaceful coexistence, and promoted the establishment of a new type of international relationship with the core of cooperation and mutual benefit under the overall orientation of the community of interests and destiny. In the process of China's National governance modernization, international relations as exogenous variables have an important influence on the development of governance system and capability modernization, and the international status and influence of China in the world and international relations have influenced the stability and development of the domestic political society in some degree. In the governance of cross-border telecom network fraud, China needs the coordination of interests and judicial assistance from relevant regions and countries, for example, in early 2000, China signed the Joint Declaration on Cooperation between China and ASEAN in the field of non-traditional security issues, and The Government of ASEAN member States and the Government of the People's Republic of China have established a preliminary operational mechanism for cooperation in combating transnational crime, such as memorandum of Understanding on cooperation in non-traditional security issues and joint statement of the general meeting of the members of the ASEAN member states. China should exert its own initiative and actively cooperate with international forces to crack down on the crime of cross-border telecom network fraud, in the context of the persistent and high numbers of cross-border frauds. 


\subsubsection{Domestic Related Industry Should Be Joint}

In order to prevent the crime of fraud in telecom network, it is necessary to standardize the legal and technical aspects of the communication and financial industry. Telecom enterprises should actively do a good job of real-name system for cellphones. They should ensure that the personal information of telecommunications business can be real and safe access to the database of telecommunications enterprises, access to user information in the network to enter the database and set up a corresponding database platform for management and prevent the user's personal information leakage. To strengthen the communication industry self-discipline, they should have a serious and responsible attitude to customers who resist spam messages and intercept fraudulent text messages. In the field of technical investigation, telecom enterprises should actively support the work of public security organs. They need to cooperate with the public security organs to quickly find out the foreign network to change the telephone into our country's international port bureau landing point and cut off, and actively found the fraudulent telephone clues to help the public security organs to counter the location of telecommunications fraud in the territory. The bank itself has the advantage of bank account management, sealing off the functions of bank account, including restricting the function of funds decomposition, transfer function, and withdrawal amount. Banks and other financial institutions should actively cooperate with the public security and other judicial organs to carry out evidence work, according to law to carry out social responsibility of publicity, prevention and combating crime. We should clear the responsibility of industry supervision which establish and implement the system of supervision responsibility to impel the industry and staff to strictly check (Lin, 2013).

\subsubsection{Strengthen the Consciousness of National Precaution}

To enhance the awareness of national information security and to prevent the awareness of the network fraud, we need the countrymen themselves to realize the complexity of society and the potential danger increase in the information age. And we also should be vigilant in mind and avoid the existence of fluke and blind self-confidence (Wang, 2017). We should encourage the national to dare to fight against the crime, discover the problem timely report, assemble the whole society to compress the existence space of the telecom swindle crime to the maximum extent, and cooperate with the national forces to govern the telecom network swindle. Ministry of Education, Ministry of Public Security and other government departments should use the reporting site, the opening of 110 anti-fraud petitioners channels, to increase the publicity efforts, strengthen the legal system, promote the core values of socialism, and exert social positive energy. With the help of television media, network media and other propaganda channels, we use omni-directional, visualization and visual publicity and education to mobilize the national attention and participation of the anti-telecom fraud, while improving the anti-telecom fraud awareness and prevention ability. 


\section{Conclusion}

In a word, we must combine the forces of society and increase the consciousness of the people, and use the power of all parties to govern cross-border telecommunications network fraud.

\section{References}

Cai, F. F. (2017). Research on Criminal Countermeasures of Telecom Fraud Crime. Xinjiang: Xinjiang University.

Ge, X. R, \& Liu, J. (2009). An International Ethic Interpretation of Ethnic and Religious Issues in Southeast Asia. Heilongjiang National Series, 6, 57-61.

Hu, X. Y, Liu, X. W., \& Peng, W. (2010). Research on the Countermeasures of Telecom Fraud Crime Control. Journal of Chinese People's Public Security University: Social Sciences Edition, 5, 90-98.

Huang, R. W. (2013). The Reconstruction of Interests and Values in Contemporary International Relations. International Survey, 6, 1-6.

Huang, X. L., \& Wang, Z. C. (2016). On International Cooperation in Punishing and Preventing the Crime of Telecom Traud-With the Background of Large Data Age. Guizhou Social Sciences, 2, 164-168.

Lin, L. (2013). Analysis on the Crime of Telecom Fraud. Beijing: Graduate School of Cass.

Wang, J. (2017). Analysis on the Victimization of Telecom Network Fraud. Journal of Beijing Police College, 5, 1-10.

Xuan, G. W. (1984). On the Crime of Swindling. Journal of Social Sciences, 4, 48-49. 